\title{
The Extent to which Jordanian Organizations Are Committed to Implementing Knowledge Management According to Jordanian Government Standards
}

\author{
Khaked M. Aldiabat ${ }^{1}$, Shireen M. AlAli ${ }^{1}$, Yasser I. Momani ${ }^{1}$ \\ ${ }^{1}$ Business Administration College, Ajloun National University, Jordan \\ Correspondence: Khaked M. Aldiabat, Business Administration College, Ajloun National University, Jordan.
}

Received: December 10, 2018

Accepted: January 17, 2019

Online Published: January 21, 2019

doi:10.5539/ibr.v12n2p143

URL: https://doi.org/10.5539/ibr.v12n2p143

\begin{abstract}
The study aimed to identify the extent to which Jordanian organizations are committed to implementing knowledge management according to Jordanian government standards, and the extent to which knowledge management standards are applied in Jordanian organizations. To highlight the problem of the study, the subcriteria for knowledge management were discussed, which includes the ability of the organization to: the commitment of senior management to knowledge management and awareness of its importance, knowledge resource identification, knowledge management and knowledge outcomes standard. The study community is from all organizations and directorates in the Kingdom of Jordan. The study sample consists of (85) organizations and directorates, who all applied for the King Abdullah II Award for Excellence in Government Performance and Transparency.

The results of the study showed that Jordanian organizations are not committed to the standard of commitment of senior management to implement knowledge management, and the lack of commitment of the Jordanian organizations to the criteria of the main performance indicators to measure the achievement of knowledge objectives and knowledge exchange indicators, while there is a commitment in the Jordanian organizations to the standard of knowledge management. The most important recommendation of the study is the need to develop a comprehensive strategy for the application of knowledge management within the organization; the study recommends further studies in the area of knowledge management since it is a new management concept.
\end{abstract}

Keywords: Jordanian organizations, knowledge management application, Jordanian government standards

\section{Introduction}

With the tremendous technological advances and the evolution of the information revolution, many sophisticated means and uses of knowledge management have emerged in achieving the objectives of management in a scientific way based on the means of modern technology (Batayneh \& El-Mashkaba, 2010). Therefore, the socalled knowledge management has emerged. Knowledge management is one of the latest management concepts. Business processes, which are the processes that assist organizations in generating, acquiring, selecting, organizing, using and disseminating knowledge to take advantage of important information and expertise that the organization possesses, which are necessary for administrative activities such as decision-making(Hamoud, 2010). Knowledge management assists organizations in generating, acquiring, selecting, organizing, using, disseminating, and disseminating important information and experiences that are essential to various administrative activities such as decision making, problem solving, learning and strategic planning (AlKhatib \& Zegan 2009). Knowledge management is gaining importance through the objectives it seeks to achieve. The primary objective of knowledge management is to provide the organization with permanent knowledge and translate it into practical behavior that serves the organization's goals by achieving efficiency and effectiveness by planning and organizing knowledge efforts that lead to the achievement of the organization's strategic and operational objectives (Dahir, 2014). So, the organization focuses on the causes of knowledge, as sound and adequate knowledge is the essence of wisdom and creativity, it provides the potential and competitive capabilities. The organization concerned with the identification and source of knowledge, the handling, classification, storage and use of information, where appropriate, which provide management, data, statistics and information to predict the risks to the organization that are capable of sustaining in the face of intense 
competition. Knowledge management is one of the most recent managerial concepts that have an effective impact on the success of businesses and organizations (Alzyadat \& Awad, 2008) . Over the years, there has been a growing interest from organizations worldwide to adopt the concept of knowledge management.

At the level of the Hashemite Kingdom of Jordan, Jordanian governmental organizations are looking for organizations to be knowledge-based, especially since the King Abdullah II Award for Excellence in Government Performance and Transparency has adopted knowledge management as a standard of excellence (Award Guide, 2015). On this basis, Jordanian governmental organizations started to implement knowledge management initiatives, especially that the award aims at making a qualitative leap in the performance of the governmental organizations in serving the Jordanian citizens and investors as well as enhancing competitiveness by spreading awareness of the concepts of outstanding performance, creativity, quality and transparency. The government sector carries out the duties and tasks assigned to it effectively, with high levels of quality, efficiency and professionalism (Award booklet, 2014). The prize aims to enhance the exchange of experience between public sector institutions and share each other success stories in practices "The Award provides a benchmark for measuring the progress and development of the performance of government organizations in the Kingdom, contributes to the development of the government sector and improves its performance, and assists in supporting the development and strategic planning programs of these organizations (Award site, 2018).

The importance of the study in terms of the Jordanian organizations' application of knowledge management in accordance with the criteria of the King Abdullah II Award for Excellence in Government Performance and Transparency within Jordanian Organizations is an attempt to answer the outstanding questions and issues related to knowledge management and its application in Jordan. In addition to the fact that the subject of knowledge management has become a source of excitement and interest in the present time, especially as organizations are always seeking to develop and renew, knowledge management is one of the main means that lead these organizations to the top in the presence of competition.

Therefore, the main problem of study is the extent to which organizations are committed to implementing knowledge management according to Jordanian government standards and the extent to which knowledge management standards are applied in Jordanian organizations. Especially since the Jordanian governmental organizations are moving towards knowledge management as an activity that the organization excels over its competitors. As the Hashemite Kingdom of Jordan does not enjoy the abundance of natural resources, its organizations are in dire need of a direction towards knowledge management in order to achieve competitive advantage. It has become clear that knowledge has a great role in building and achieving outstanding performance. Knowledge capacity can be derived from knowledge and methods in finding excellence on the competitor.

In order to highlight the problem of the study, the sub-criteria for knowledge management will be discussed, which includes the ability of the organization to (Award criteria, 2016): the commitment of senior management to knowledge management and awareness of its importance, the identification of sources of knowledge that include data and information, internal and external knowledge assets, and normative comparisons; implementation, confidentiality, and security of information, review and evaluation, and addresses the knowledge outcomes standard: key performance indicators to measure the achievement of knowledge objectives, knowledge exchange indicators.

\section{Literature Review}

Previous studies addressed the issue of knowledge management on more than one side. (Kulkarni \& Dahiya, 2018) discussed implementation barriers for knowledge management for small and medium-sized enterprises (SME). The survey is based on a survey of Indian cities in Delhi, Pune and Ahmed Najjar. Using statistical analysis methods, barriers to the use of knowledge management in SMEs in India have been investigated such as information and communication technology, human resources, organizational level, and market level. The study showed a clear view of these organizations that have a problem identifying relevant knowledge to store or they can not figure out what they will need in the future. Another tangible outcome is the rapid change in IT tools that create a time lag between FAO's work and response due to the time needed to identify new technology.

The study (Tan, at, el., 2018) highlighted the factors affecting the implementation of knowledge management among SMEs in Malaysia, as the Malaysian Government is actively involved in the implementation of the ETP, the Government Transition Program (GTP) (UTP). This study was conducted to measure SME acceptance of knowledge management and identify the pros and cons of knowledge management. The questionnaire was used to collect data and randomized the sample to identify respondents. The questionnaire was developed and customized based on knowledge management and IT management frameworks. In this model, the dependent 
variable was the adoption of knowledge management organizations. Independent variables included knowledge application needs, knowledge engineering, knowledge infrastructure, knowledge investment and knowledge principles. The study found that there is a lack of adoption of knowledge management by organizations; moreover, there is a difficulty in identifying the knowledge required to small and medium enterprises.

(Sivakumar, 2018) examined the indicators of the implementation and creation of knowledge. The study aimed to develop a comprehensive model that integrates the creation of knowledge with knowledge indicators through the work of knowledge in participation, documentation, knowledge acquisition, transfer and application of knowledge, promotion of knowledge creation within the employees and implementation of knowledge creation at work. This study examined how knowledge indicators can enhance the creation of knowledge among employees. The results showed that knowledge management indicators: participation, documentation, knowledge acquisition, transfer and application of knowledge have a 70\% impact on knowledge creation.

The study of (Sahmadi \& Prosh, 2017) aims to explore the impact of knowledge management on performance in the economic institution, by introducing knowledge management, presenting the theoretical framework of performance in the organization, and highlighting the impact of management effective knowledge of the performance components of the staff, learning, job satisfaction, and internal processes to ensure outstanding performance for the institution. Finally, it concluded that knowledge management has a positive impact on the efficiency and effectiveness of internal processes and in achieving job satisfaction for employees as well as raise their level of learning, through effective steps to manage knowledge within the institution.

The study of (Alfahout, 2018) highlighted the impact of e-administration on the knowledge management processes of employees in some Palestinian universities. The aim of this study is to identify the impact of emanagement in the knowledge management processes of senior and middle management positions in some universities in the Gaza Strip. The relationship between the five requirements of electronic management: administrative, human, technical, financial, security and knowledge management processes: diagnosis, generation, deployment, storage. The problem of the study was the impact of the use of e-administration in knowledge management processes among the senior and middle management positions in the Palestinian universities. This study was based on two analytical descriptive and exploratory approaches, as well as the study used the stratified random sampling method and the questionnaire as the primary tool for collecting primary data.

The study of (Shahid \& Boushamin, 2018) entitled "Knowledge Management and its Impact on Decision Making in the Institution", highlighted the impact of knowledge management on the effectiveness of decision making at Tahrir University level. To answer the problem presented and to verify the hypotheses, we conducted this study on a sample of the staff of the university. The analytical descriptive method was used. A 34-question questionnaire was designed to answer the question of how the impact of knowledge management on decisionmaking effectiveness. We relied on the analysis of results and hypothesis testing on SPSS, the results of the study were: there are statistically significant differences between the requirements of knowledge management and the effectiveness of decision making.

The study (Othmani \& Emran, 2018) discussed the role of knowledge management in the achievement of the strategy of excellence in the economic institution, which aimed to identify the impact of knowledge management in achieving the excellence strategy in the Condor Foundation. In order to achieve the objectives of the study, the questionnaire was used as a main tool in collecting data analyzed by accreditation using the statistical package (SPSS). The study reached a number of results, the most important of which was the existence of a statistically significant relationship of knowledge management to the achievement of the excellence strategy in the institution under study, with no statistically significant differences between the responses of the respondents on the subject of the study due to differences in personal and professional variables. In the light of the findings, the study presented a set of recommendations on this subject.

The study of (Hamdeh, 2018) unveiled knowledge management requirements in the Ministry of Higher Education in the Sultanate of Oman from the point of view of administrative staff in the Department of Education. The results of the study showed the importance of the four domains (knowledge generation, application of knowledge, knowledge dissemination and knowledge storage), respectively, at the level of gender, job title, age, scientific qualification and number of years of experience in the present job at the significance (0.05). As for the impact of the variables of the study, the results indicated that there is no difference in the requirements of applying knowledge management in the Ministry of Higher Education in the Sultanate of Oman from the point of view of the middle administrators, the variables of study, gender, job title and the years of experience in the current job. The study concluded with a number of recommendations, including: the need to prepare lectures and training courses for all employees in the Ministry of Higher Education in order to make 
them aware of the importance of applying knowledge management requirements to increase their awareness of them in terms of knowledge and practice.

The study of (Abu Amra \& Nasr Allah, 2018) discussed the role of knowledge management in the development of the performance of government colleges in Gaza Strip. The study aimed to discuss the role of knowledge management in the development of the performance of government colleges in Gaza Strip. To achieve the objectives of the study, the researchers relied on the secondary data which contributed to the theoretical framework of the research, in addition to the preliminary data provided by designing a questionnaire consisting of six dimensions that affect the development of performance: knowledge culture, organizational leadership, awareness and knowledge commitment, human capital, technology and infrastructure, and application of knowledge, it was distributed to 59 employees of the College, and the study reached the high level of knowledge management in the Technical College of Palestine from the point of view of workers, performance development level at Palestine Technical College. In addition, the staffs of the college have close views on the practice of knowledge management and its role in the development of performance in terms of gender or nature of scientific qualification or nature of the work. The study recommended the need to pay attention to the generation of knowledge and the development of storage methods and expand the process of sharing by providing the environment appropriate for knowledge empowerment, to build an organizational culture that embraces knowledge management as a methodology.

Although the studies dealt with the subject of knowledge management by different environments, this study came to recognize the extent to which the Jordanian organizations are committed to applying knowledge management according to the Jordanian government standards in order to understand the importance of knowledge management and application within these organizations, and to highlight the criteria of the award, especially that knowledge management is one of these criteria, and stand at the key performance indicators to measure the achievement of the goals of knowledge management as well as measuring the success of the achievement within the Jordanian organizations, and knowledge of the constraints and reasons that limit the application of knowledge management, and then try to develop solutions to these obstacles.

\section{Methodology of the Study}

The study relied on the descriptive analytical method for the completion of the study by using the following sources to collect the data as follows:

A) Secondary data sources: they include books, studies, Arab and foreign sources, publications, regulations and instructions issued by the relevant academic, governmental and professional bodies in paper and electronic form.

B) Primary data sources: Data on the commitment of Jordanian organizations to implement the standards were accessed through frequent visits to the King Abdullah II Award for Excellence in Government Performance and Transparency, and through the results of the knowledge management performance of the Award.

\subsection{Community and Sample of the Study}

The study community consists of all organizations and directorates in the Kingdom of Jordan. A sample of (85) organizations and directors were selected, all of whom are candidates for the King Abdullah II Award for Excellence in Government Performance and Transparency.

\section{Results and Discussion}

This section presents the results of the statistical analysis of the current study, which aims to identify "the extent of the commitment of organizations to implement knowledge management according to the standards of the Jordanian government" and the extent to which the application of knowledge management standards in Jordanian organizations.

First: The proposed grades of the Knowledge Management Standard were adopted from the King Abdullah II Award for Excellence in Government Performance and Transparency. The following equation was used to measure the degree of evaluation of the standards:

Length $=$ (highest of standard - lowest of standard) $/ 3$

Table (1) shows the assessment grade for all knowledge criteria. 
Table 1. Degree rating for each of the knowledge criteria

\begin{tabular}{|c|c|c|c|c|}
\hline \multirow{2}{*}{ Standards } & \multirow{2}{*}{ Total Degree } & \multicolumn{3}{|c|}{ Degree of assessment } \\
\cline { 3 - 5 } & & Low & Medium & High \\
\hline Commitment & $\mathbf{1 5}$ & $\mathbf{0 - 5 . 0 0}$ & $\mathbf{5 . 0 1 - 1 0 . 0 0}$ & $\mathbf{1 0 . 0 1 - 1 5 . 0 0}$ \\
\hline Commitment of senior management & 15 & $0-5.00$ & $5.01-10.00$ & $10.01-15.00$ \\
\hline Sources of knowledge & $\mathbf{3 0}$ & $\mathbf{0 - 1 0 . 0 0}$ & $\mathbf{1 0 . 0 1 - 2 0 . 0 0}$ & $\mathbf{2 0 . 0 1 - 3 0 . 0 0}$ \\
\hline Data and information & 10 & $0-3.33$ & $3.34-6.33$ & $6.34-10.00$ \\
\hline Internal knowledge assets & 10 & $0-3.33$ & $3.34-6.33$ & $6.34-10.00$ \\
\hline External cognitive needs & 5 & $0-1.66$ & $1.67-3.33$ & $3.34-5.00$ \\
\hline Standard comparisons & 5 & $0-1.66$ & $1.67-3.33$ & $3.34-5.00$ \\
\hline knowledge management & $\mathbf{4 0}$ & $\mathbf{0 - 1 3 . 3 3}$ & $\mathbf{1 3 . 3 4 - 2 6 . 6 6}$ & $\mathbf{2 6 . 6 7 - 4 0 . 0 0}$ \\
\hline Planning and implementation & 20 & $0-6.66$ & $6.67-13.32$ & $13.32-20.00$ \\
\hline Confidentiality and security of information & 10 & $0-3.33$ & $3.34-6.33$ & $6.34-10.00$ \\
\hline Review and evaluation & 10 & $0-6.66$ & $6.67-13.32$ & $13.32-20.00$ \\
\hline Knowledge results & $\mathbf{3 0}$ & $\mathbf{0 - 1 0 . 0 0}$ & $\mathbf{1 0 . 0 1 - 2 0 . 0 0}$ & $\mathbf{2 0 . 0 1 - 3 0 . 0 0}$ \\
\hline $\begin{array}{c}\text { Key performance indicators to measure the } \\
\text { achievement of knowledge objectives }\end{array}$ & 20 & $0-6.66$ & $6.67-13.32$ & $13.32-20.00$ \\
\hline Knowledge exchange indicators & 10 & $0-3.33$ & $3.34-6.33$ & $6.34-10.00$
\end{tabular}

Second: the arithmetical averages and standard deviations to assess the extent to which organizations adhere to the application of knowledge management according to the standards of the Jordanian government and the results of the application of the One Sample T-test. The percentage was calculated according to the following equation $=$ (the arithmetic mean of the performance of companies on the standard / total score of the criterion) $\times$ $100 \%$, the equation was used to standardize the one sample T-test (50\%).

Table 2. The statistical averages and standard deviations to assess the extent to which Jordanian organizations are committed to applying knowledge management according to the senior management compliance standards and the results of One Sample T-test

\begin{tabular}{ccccccccc}
\hline Standards & $\begin{array}{c}\text { Lowest } \\
\text { value }\end{array}$ & $\begin{array}{c}\text { Highest } \\
\text { value }\end{array}$ & $\begin{array}{c}\text { Arithmetic } \\
\text { al average }\end{array}$ & $\begin{array}{c}\text { Standard } \\
\text { deviation }\end{array}$ & Percentage & $\begin{array}{c}\text { Degree of } \\
\text { assessment }\end{array}$ & $\begin{array}{c}\text { T } \\
\text { Significant } \\
\text { level }\end{array}$ \\
\hline $\begin{array}{c}\text { Senior management } \\
\text { commitment }\end{array}$ & 2.50 & 9.72 & 5.68 & 1.65 & 37.8 & Medium & -10.144 & 0.00 \\
\hline
\end{tabular}

Table (2) shows that the commitment of Jordanian organizations to apply knowledge management according to the senior management commitment level ranged between (2.50-9.72), the mean was (5.68) and the standard deviation was (1.65), indicating that the level of commitment of the organizations to apply management Knowledge on this criterion is average, as shown from the table that the value of $(T)$ was $(-10.144)$ which is a negative value and a statistical function at the level of significance $(\alpha \leq 0.05)$ indicating a value gap on the commitment of senior management to implement knowledge management by $(50 \%)$.

\begin{tabular}{lcccccccc}
\hline Standards & $\begin{array}{c}\text { Lowest } \\
\text { value }\end{array}$ & $\begin{array}{c}\text { Highest } \\
\text { value }\end{array}$ & $\begin{array}{c}\text { Arithmetical } \\
\text { average }\end{array}$ & $\begin{array}{c}\text { Standard } \\
\text { deviation }\end{array}$ & Percentage & $\begin{array}{c}\text { Degree of } \\
\text { assessment }\end{array}$ & T & Significant level \\
\hline Data and information & 1.30 & 6.60 & 3.40 & 0.96 & 34.0 & Medium & -15.197 & 0.00 \\
Internal cognitive assets & 1.30 & 5.50 & 3.39 & 0.95 & 33.9 & Medium & -15.503 & 0.00 \\
Internal cognitive needs & 0.87 & 3.56 & 2.05 & 0.58 & 41.0 & Medium & -7.111 & 0.00 \\
Standard comparisons & 0.80 & 3.40 & 1.78 & 0.57 & 35.6 & Medium & $-11.469-$ & 0.00 \\
Knowledge sources & $\mathbf{4 . 3 3}$ & $\mathbf{1 7 . 4 1}$ & $\mathbf{1 0 . 6 1}$ & $\mathbf{2 . 8 2}$ & $\mathbf{3 5 . 4}$ & Medium & $\mathbf{- 1 4 . 2 5 5}$ & $\mathbf{0 . 0 0}$ \\
\hline
\end{tabular}

Table 3. The statistical averages and standard deviations to assess the extent to which Jordanian organizations are committed to applying knowledge management according to the standard of knowledge sources and the results of the One Sample T- test.

Table (3) shows that the Jordanian organizations' commitment to applying knowledge management according to the knowledge source standard ranged between (4.33-17.41), the mean was (10.61) and the standard deviation was (2.82). This indicates that the level of commitment of organizations to implement knowledge management on this criterion was average, the table shows that the value of $(\mathrm{T})$ is $(-14.25)$, which is a negative value and a statistical function at the level of significance $(\alpha \leq 0.05)$. This indicates that there is a value gap on the standard of knowledge sources with the standard mark (50\%). 
Table 4. The statistical averages and standard deviations to assess the extent to which Jordanian organizations are committed to applying knowledge management according to the knowledge management standard and the results of the One Sample T-test.

\begin{tabular}{ccccccccc}
\hline Standards & $\begin{array}{c}\text { Lowest } \\
\text { value }\end{array}$ & $\begin{array}{c}\text { Highest } \\
\text { value }\end{array}$ & $\begin{array}{c}\text { Arithmetic } \\
\text { al average }\end{array}$ & $\begin{array}{c}\text { Standard } \\
\text { deviation }\end{array}$ & Percentage & $\begin{array}{c}\text { Degree of } \\
\text { assessment }\end{array}$ & $\begin{array}{c}\text { Significant } \\
\text { level }\end{array}$ \\
\hline $\begin{array}{c}\text { Implementation } \\
\text { and planning }\end{array}$ & 3.00 & 13.92 & 8.12 & 2.51 & 40.6 & Medium & $6.891-$ & .0000 \\
$\begin{array}{c}\text { Confidentiality } \\
\text { and security of } \\
\text { information }\end{array}$ & 2.17 & 9.78 & 6.06 & 1.66 & 60.6 & Medium & $6.891-$ & .0000 \\
$\begin{array}{c}\text { Review and } \\
\text { assessment } \\
\begin{array}{c}\text { Knowledge } \\
\text { management }\end{array}\end{array}$ & 3.00 & 8.75 & 6.49 & 1.87 & 67.5 & Medium & 11.38 & .0000 \\
\hline
\end{tabular}

Table (4) shows that the commitment of Jordanian organizations to applying knowledge management according to the knowledge management standard ranged between (8.67-36.28), the mean was (21.67) and the standard deviation was (6.33), indicating that the-level of commitment of organizations to implement knowledge management was average. The value of $\mathrm{T}$ is 2.414 , which is positive and statistically significant at $(\alpha \leq 0.05)$. This indicates that there is no value gap on the knowledge management standard with the standard mark (50\%).

Table 5. The statistical averages and standard deviations to assess the extent to which Jordanian organizations are committed to applying knowledge management according to the results of knowledge standard and the results of applying one sample T-test.

\begin{tabular}{lcccccccc}
\hline Standards & $\begin{array}{c}\text { lowest } \\
\text { value }\end{array}$ & $\begin{array}{c}\text { Highest } \\
\text { value }\end{array}$ & Mean & $\begin{array}{c}\text { Standard } \\
\text { deviation }\end{array}$ & percentage & $\begin{array}{c}\text { Assessment } \\
\text { value }\end{array}$ & T & $\begin{array}{c}\text { Statistical } \\
\text { significance }\end{array}$ \\
\hline $\begin{array}{l}\text { Key performance } \\
\text { indicators to measure } \\
\text { the achievement of }\end{array}$ & 3.89 & 24.33 & 8.38 & 4.68 & 41.9 & Medium & -3.162 & .0000 \\
$\begin{array}{l}\text { knowledge objectives } \\
\begin{array}{l}\text { Knowledge exchange } \\
\text { indicators }\end{array}\end{array}$ & 1.78 & 7.92 & 3.06 & 1.67 & 30.6 & Medium & -10.67 & .0000 \\
Knowledge results & $\mathbf{5 . 8 3}$ & $\mathbf{3 0 . 2 9}$ & $\mathbf{1 1 . 4 6}$ & $\mathbf{5 . 8 6}$ & $\mathbf{3 8 . 2}$ & Medium & $\mathbf{- 5 . 5 4 2}$ & $\mathbf{. 0 0 0 0}$ \\
\hline
\end{tabular}

Table (5) shows that the commitment of Jordanian organizations to apply knowledge management according to the knowledge results criterion ranged between (5.83-30.29), the mean was (11.46) and the standard deviation was (5.86). This indicates that the level of commitment of organizations to implement knowledge management was average. The value of $\mathrm{T}$ is 10.670 , which is negative and statistically significant at the $(\alpha \leq 0.05)$ level. This indicates that there is a value gap on the standard of knowledge results with the standard mark forming (50\%).

\section{Conclusion}

The study aimed to identify the extent to which organizations adhere to the application of knowledge management according to the Jordanian government standards issued by the King Abdullah II Award for Excellence in Government Performance and Transparency and the extent to which knowledge management standards are applied in Jordanian organizations. In order to highlight the problem of the study, the sub-criteria for knowledge management were discussed, which includes the ability of the organization to: The commitment of senior management to knowledge management and awareness of its importance, Identification of knowledge sources that include data and information, internal and external knowledge assets, normative comparisons. Implementation, confidentiality, and security of information, review and evaluation, and addresses the knowledge outcomes standard: key performance indicators to measure the achievement of knowledge objectives, knowledge exchange indicators.

One of the findings of the study is the lack of commitment by Jordanian organizations to the standard of commitment of senior management to the implementation of knowledge management, the non-compliance of Jordanian organizations with the criteria of knowledge sources. This study agreed with the results of the study (Kulkarni, Dahiya, 2018) which showed that organizations have a problem in identifying relevant knowledge to store or that they cannot know what they will need in the future, and that Jordanian organizations do not adhere to the criteria of the main performance indicators to measure the achievement of knowledge objectives and knowledge exchange indicators. The study contrasted with the findings of the study (Tan, 2018, at), which found that there is a lack of adoption of knowledge management by organizations and also there is difficulty in identifying the knowledge required of small and medium organizations. The results of the study were also agreed with Sivakumar (2018) which showed that knowledge management indicators: participation, documentation, 
knowledge acquisition, knowledge transfer and application have a 70\% impact on knowledge creation.

The study recommends providing mentors and specialists by the King Abdullah II Award for Excellence in Government Performance for organizations to raise awareness of the importance and application of knowledge management. The organizations adopt the concept and how to apply knowledge management and dissemination by holding training courses and distributing publications on the importance of knowledge. It also recommends the development of a comprehensive strategy for the application of knowledge management within the organization, including knowledge maps, evidence of internal knowledge transfer, a list of vital knowledge assets in organizations, documentation of external knowledge needs. The study also recommends further studies in the area of knowledge management, especially it is a new management concept.

\section{References}

Abu Amra, S., \& Nasr Allah, A. (2018). Role of knowledge management in the Gaza Strip. Journal of Development and Human Resources Management, 5.

Al Khatib, A., \& Zegan, K. (2009). Knowledge management and information systems. Irbid, the world of modern books.

Alfahout, K. (2018). The Impact of E-Management Recruitment on Knowledge Management Operations An unpublished PhD thesis, Sudan University of Science and Technology, School of Business Studies, Khartoum.

Alzyadat, M., \& Awad, A. (2008). Contemporary Trends in Knowledge Management Amman, Dar Al Safa Publishing and Distribution.

Award criteria. (2016). King Abdullah II Award for Excellence in Government Performance and Transparency. Award criteria, third cycle.

Award Guide. (2015). King Abdullah II Award for Excellence in Government Performance and Transparency. Third session. Award booklet. (2014). King Abdullah II Award for Excellence in Government Performance and Transparency. Award booklet. Third session.

Award site. King Abdullah II Award for Excellence in Government Performance and Transparency. http://www.kaa.jo/default.aspx

Batayneh, M., \& El-Mashkaba, Z. (2010). Knowledge management, between theory and practice. Oman. Dar Jallis Al Zaman for Publishing and Distribution.

Dahir, N. (2009). Knowledge Management. Irbid, the world of modern books for publication and distribution.

Hamdeh, B. (2018). Knowledge Management Application Requirements in Saudi Arabia. Volume VI, Number 12.

Hamoud, K. (2010). Knowledge Organization. Amman. Dar Al Safa for Publishing and Distribution.

Kulkarni, R., \& Dahiya, R. (2018). Implementation Barriers for Knowledge Management: For SMEs in Indian Construction Industry. Retrieved from http://urn.kb.se/resolve?urn=urn:nbn:se:kth:diva-231747.

Othmani, E., \& Emran, A. (2018). The role of knowledge management in economic progress. Journal of Social Sciences and Humanities, 9.

Sahmadi, E., \& Brosh, Z. (2017). The application of imported operations was considered a field study on the National Telecommunications Company Mobilis. Journal of the performance of Algerian institutions, 12.

Shahid, H., \& Boushamin, A. (2018). Knowledge Management or Accountability: Taheri Mohammed Bashar University. Journal of Financial, Accounting and Administrative Studies, 9.

Sivakumar, K. (2018). Knowledge Indicators for Implementation of Knowledge Creation: A Critical Examination Using Structural Equation Modeling. IUP Journal of Knowledge Management, 16(3), 30-43.

Tan, K., Yuen, Y., \& Ha, L. (2018). Factors affecting knowledge governance implementation among Malaysian SMEs. Management Science Letters, 8(5), 405-416.

\section{Copyrights}

Copyright for this article is retained by the author(s), with first publication rights granted to the journal.

This is an open-access article distributed under the terms and conditions of the Creative Commons Attribution license (http://creativecommons.org/licenses/by/4.0/). 